\title{
CULTIVATION OF VEGETABLES AND FISH USING THE AQUAPONICS SISTEM (DFT MODEL) IN CV TMR
}

\author{
Wawan Gunawan ${ }^{1}$, Sofiyan Firdaus ${ }^{2}$, Bambang Ali G ${ }^{3}$ \\ ${ }^{1,2,3}$ Universitas Banten Jaya, Jl Syech Nawawi Albantani Serang, Banten, Indonesia \\ Email: wawan.gunawan@unbaja.ac.id
}

\begin{abstract}
Communities and companies in Indonesia are experiencing economic difficulties due to the corona pandemic (covid-19). The aim of this service is to help communities or companies affected by Covid-19 through the application of environmentally friendly technology, easy to apply and generate benefits for partners, especially partner employees who laid off in order to work again, there are applied technologies used are aquaponic techniques, namely the cultivation of vegetables and fish that are mutually beneficial, the method of cooperation used is a partnership with one of the companies affected by Covid-19 (CV TMR), utilization of goods or materials that have been unused land in the partner also optimizes empty land to be used and utilized into productive areas. The aquaponics model used is the DFT (Deep Flow Technique) system, DFT is a hydroponic planting system that uses puddles in the installation and uses slow-flow circulation. This system uses electricity as a pump drive so that it can easily circulate nutrition throughout the plant, thus the benefits of this DFT system are that food nutrition from the bottom of the pond is distributed well to all plant roots so that plants grow more fertile and fish are healthy because the dirt in the pond becomes. The process of making it until the fish harvest is 3 months with the results of the partners getting an additional income of 1,632,000, while the benefits that the partners get are that the environmental area becomes more beautiful, comfortable and becomes an attraction for visitors. for the next program an aquaponics system will be made on land of $30 \mathrm{~m} x 1.5 \mathrm{~m}$ with the assumption of ten times the profit per harvest (per three months).
\end{abstract}

Keywords: CV TMR; Coved-19; Cultivation; Aquaponics; DFT.

\section{INTRODUCTION}

Since the emergence of the corona virus outbreak at the end of 2019, which we know as covid-19, several countries including Indonesia have experienced enormous economic losses, several companies have gone out of business, even small and medium enterprises have experienced a significant impact, including the service business, especially the hotel business. and tourism went into major bankruptcy. (The Coordinating Ministry for Economic Affairs of the Republic of Indonesia,2020). CV Tirta Mas Raya (TMR) is a medium-sized company engaged in the tourism sector and sports facilities rental services are the impact of Covid-19.

To overcome the impact of Covid-19, the government has made various efforts in the Medium and Small Business (MSB) sector so that the wheels of the economy can run by providing stimulus assistance as like placing low-interest funds in banks, providing interest subsidy programs for People's Business Credit (KUR) loans for UMKM business actors, assisting the productive president for UMKMs. Where each UMKM was given assistance worth IDR 2.4 million. And banking restructuring, but the results have not been able to recover as 
before and still need assistance from various parties, including academia, so that the wave of layoffs can be controlled.

CV. Tirta Mas Raya (TMR) is a business entity that has a history and experience in providing sports facilities and infrastructure such as swimming pools and badminton courts. The company has been conducting its business activities since its establishment in 2014, as a business intended for the public. On 9 September 2016 CV. Tirta Mas Raya (TMR) was formed, marked by the issuance of the notarial deed of Veronika Sri Hartati, SH., Which is registered in the SK MENKEH RI NO. C-791.HT.03.01-TH. 1999, dated March 23, 1999.

CV. Tirta Mas Raya (TMR) operates in the East Serang area, especially in Ciruas District, which has a strategic location and has great potential in the future in the field of sports facilities and training, this is because several housing and schools have been established around the business premises, both of which are the largest community to take advantage of the facilities at CV. Tirta Mas Raya (TMR). To help restore the condition of the company, we as academics have a social responsibility to help increase the company's income back and so that employees can work again. The idea that we offer to the company above is to use the remaining materials of the project plus the materials we bought to make an Aquaponics system. Besides this, we also saw that there was an idle land that we could reprocess into productive land with the aquaponics system.a proper eco-design is essential to limit the environmental burdens and to enhance the economic profitability (Alberto et al., 2018).

The purpose of this service is to help the company CV. Tirta Mas Raya in order to get additional income from additional business during Covid-19 by providing knowledge and technology for freshwater fish cultivation and producing vegetables by applying aquaponics technology, and utilizing residual projects in the company in areas that have not utilized properly (idle land). Aquaponics is a symbiotic ecosystem that combines two established technologies, aquaculture and hydroponics. Aquaculture is the growing and cultivation of aquatic life, including fish, crayfish, snails, shrimp, oysters and so on for food, and hydroponics is growing plants in sand, gravel, liquid or other media, but without soil.(INMED, 2017).

Combining aquaculture with hydroponics we obtain a new innovation named aquaponics which respects principles of sustainable agriculture (wastewaterbiofiltration by plants) and gives us the possibility to increase economical efficiency with an additional production(organic vegetables).(Blidariu\& Grozea, 2014). "A recirculating aquaculture system (RAS) can be defined as an aquaculture system that incorporates the treatment and reuse of water with less than $10 \%$ of total water volume replaced per day(Blidariu \& Grozea, 2014).Aquaponics is a combination of aquaculture and hydroponics which produces a symbiosis of mutualism or mutual benefit. In the aquaponics system, we can raise fish as well as plant 
vegetables simultaneously, with certain techniques the fish pond water can be converted into nutrients for vegetable plants and the water that returns to the pond is clean. The vegetables produced are also organic because they do not use chemical fertilizers in their maintenance so they are safer for consumption.There exist several system designs for recirculating aquaponics systems. The designs are based on hydroponic systems, the difference being that the water source for the aquaponics system come from the fish tank and is eventually returned to its source of origin.(Saini, 2015)

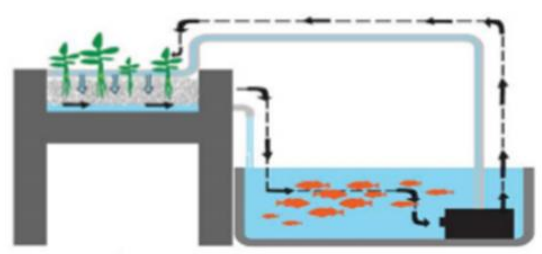

Picture 1. Water Flow by Close System (Saini, 2015)

This research has a novelty in terms of the use of used goods and optimization of vacant land as well as the use of the DFT method so that it has an impact on faster plant growth and healthier fish conditions.

\section{METHOD}

Implementation of activities carried out at CV. Tirta Mas Ciruas, Ciruas District, Serang Regency - Banten. Activities are carried out for 3 months starting from August 1, 2020 to October 30, 2020

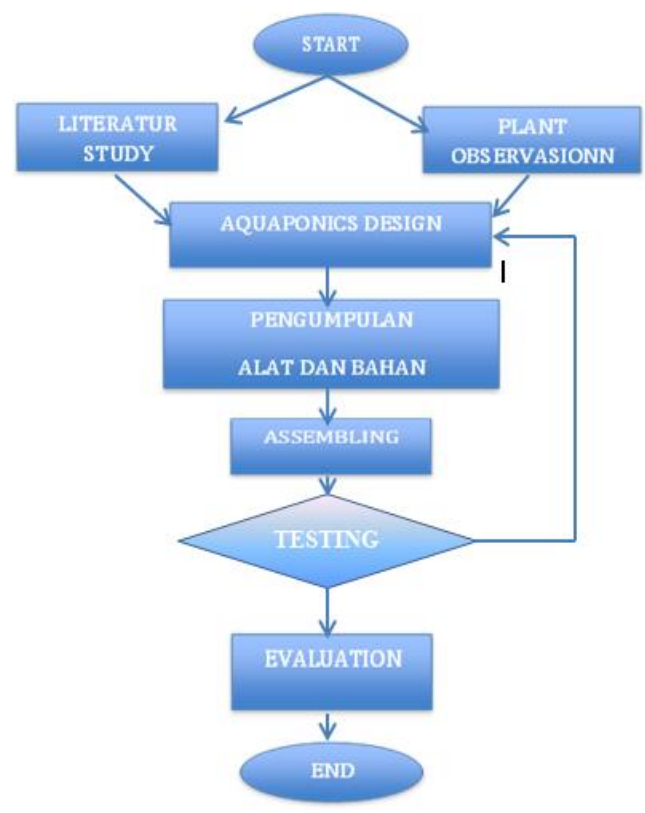

Picture 2. Steps for Making Aquaponics 
DFT aquaponic is aaquaponicmethod that circulates flowing nutrient water and leaves stagnant water in the system. The height of the inundation varies considerably, from 2 to $5 \mathrm{~cm}$. Depending on the size of the material / media used. In the case of using PVC pipes, usually the pipes used are between 2.5 inches to 4 inches in size.

In the DFT system, water that is circulated in a gutter system or PVC pipe is circulated using an electric water pump. Due to the system that leaves stagnant water, the water pump does not have to be turned on always. For example you can use a timer to make the pump start at a certain time. Suppose that it only lights up during the day or at certain times. The advantages of the DFT Hydroponic System.

1. It saves more electricity because the pump does not need to be always turned on.

2. The supply of nutrients is maintained even though there is a power cut.

3. Suitable for various types of hydroponic plants.

The DFT (Deep Flow Technique) system is a way of farming using standing water in the installation. The water, of course, already contains the nutrients needed by plants. "DFT or Deep Flow Technique is a hydroponic planting system that uses puddles in the installation and uses slow flow circulation. This system uses electricity as a pump drive so that it can easily circulate nutrition to all plant roots. The advantage of this system is that when the water pump that flows through the installation dies, there is still a puddle of water in the installation pipe.

The aquaponics system design is made based on the size of the fish pond located at the location, which is $3 \times 1.5 \mathrm{~m}$ in size, this can be in Figure 3 below.

1. Mechanical and Biological Filters

Biofilters are a prominent feature in recirculating aquaculture and in aquaponic systems. The water is treated by converting dissolved ammonia, a toxic metabolite excreted by fish, into harmless nitrate (Timmons and Ebeling, 2010). To convert fish pond water into nutrients for plants, it is necessary to process Nitrification in pond water so that pond water which still contains ammonia is converted into nitrite (NO2) and then converted into nitrate (NO3) which is a nutrient for plants. All of these processes occur in the filter we made, the filter we made used 3 (three) 20lt paint buckets. The mechanical filter functions as a water separator from the dirt in the fish pond. The biological filter functions to change pool water containing nitrite (NO2) to nitrate (NO3) with the help of nitrobacteria. 

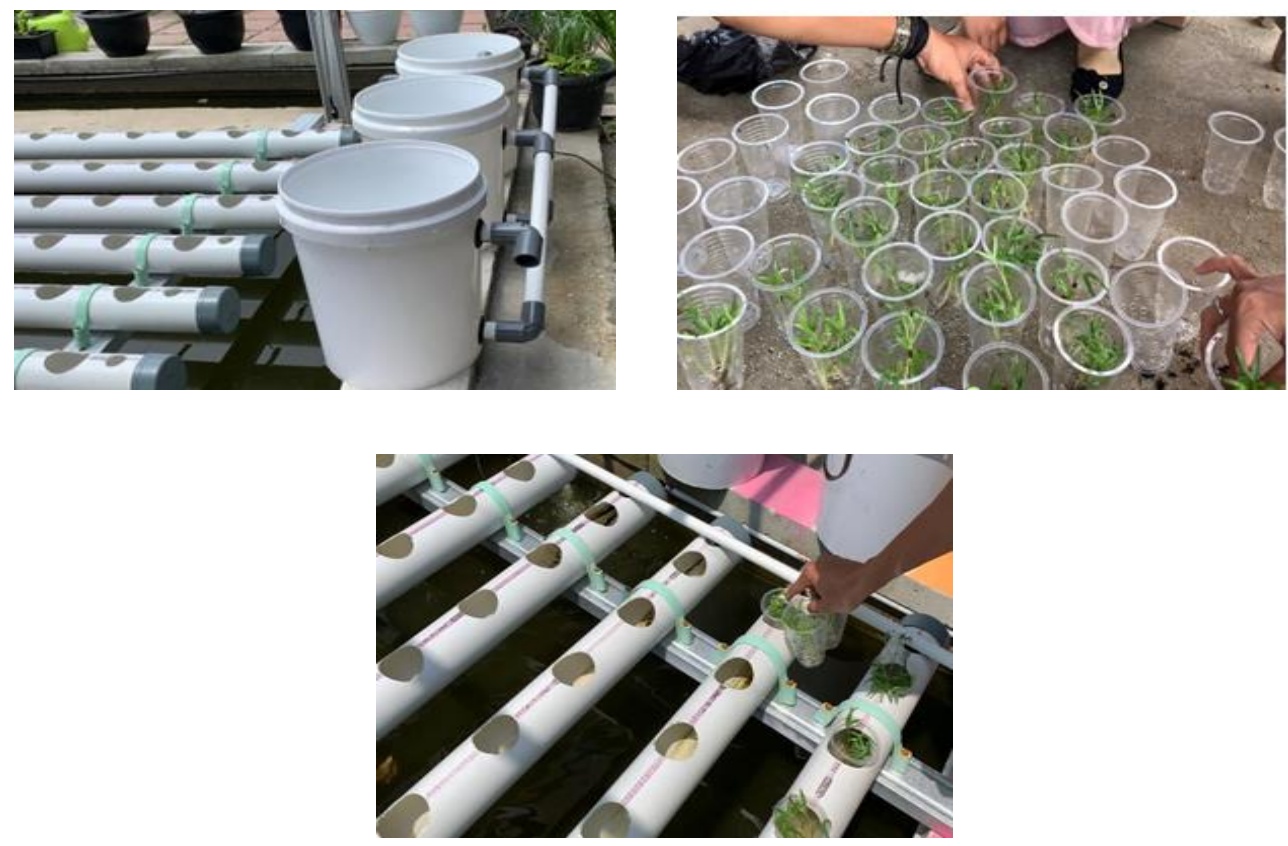

\section{Picture 3. Assembling of Filter and PVC Pipe}

2. Planting Media Installation Pipe

As a place for growing vegetables, we use 3 inches of PVC pipe with 3 sticks, then cut it into two parts to get 6 pieces of PVC pipe. For each PVC pipe, there were 12 planting holes, so that a total of 72 planting holes were obtained. At each end of the pipe, a flock sock of 3 inches to 2 inches is installed which functions as a water barrier so that there is still a puddle of water if the pump dies.

3. Data collection of equipment and material requirements according to the level of need.Selection of components in terms of price and quality of goods used so that the results achieved will be in accordance with the initial target and adjust the allocation of available funds. The data table for the material and tool requirements used is as follows

Table 1. Equipment and Material Needs

\begin{tabular}{|c|l|c|}
\hline No & \multicolumn{1}{|c|}{ Name of Goods } & Total \\
\hline 1 & PVC pipe 3 inch & 3 \\
\hline 2 & PVC Pipe 1 inch & 1 \\
\hline 3 & PVC Pipe 0.5 inch & 1 \\
\hline 4 & Knee 1 inch & 7 \\
\hline
\end{tabular}




\begin{tabular}{|c|c|c|}
\hline 5 & Knee 0.5 inch & 5 \\
\hline 6 & Stop Valve & 2 \\
\hline 7 & Pipe Dope 3 inch & 6 \\
\hline 8 & Glue & 1 \\
\hline 9 & 2 Hole Aerator 2 & 1 \\
\hline 10 & GrommetRubber 1 inch & 6 \\
\hline 11 & Canal Iron & 1 \\
\hline 12 & Amara wp-104 Pump & 1 \\
\hline 13 & Clam of Pipe (iron type) & 12 \\
\hline 14 & Ember 25 liter & 3 \\
\hline 15 & Bio Ball (Pack) & 1 \\
\hline 16 & Kale seeds contain 500 grains & 2 \\
\hline 17 & Tilapia Seeds & 200 \\
\hline 18 & Fish feed / pack & 10 \\
\hline 19 & Iron Hex sow & 1 \\
\hline 20 & Electric Bore & 1 \\
\hline 21 & Hole Saw & 1 \\
\hline 22 & Plastic Cup & 100 \\
\hline 23 & Foam Filter & 1 \\
\hline 24 & Flock shock & 6 \\
\hline 25 & Solder & 1 \\
\hline
\end{tabular}

After designing and planning tools and materials, the next step is the aquaponics system manufacturing process in accordance with what was previously planned. Therefore, making an aquaponics system must be done carefully and using predetermined standards to produce a good system.

4. Testing and Evaluation

This test is done to ensure that the aquaponics system can run as expected. The parameters that need to be tested are the flow of fish pond water to the filter buckets, the water flow from the filter bucket to the aquaponics installation PVC pipe. The evaluation phase is carried out after the aquaponics system is running. At this stage, the work system of the 
aquaponics installation will be assessed, both in terms of stability and water flow. If the results obtained are not as expected, the design, manufacture and testing stages of the system will be carried out again.

\section{RESULT AND DISCUSSION}

Aquaponics technology to be applied in a less extensive area is very suitable and can be an additional income for the community or company that will optimize idle land as best as possible. The results of training and exposure to knowledge about the installation and assembly of aquaponics systems in land with a size of $3 \times 1.5$ meters have resulted in concrete results that the company has reactivated several employees who have been sent home by managing vegetable and fish cultivation in an aquaponics system, the impact of this business. There is a change in the comfortable, beautiful and green environment compared to before, and this has become an attraction for visitors who will travel and exercise, financially it has provided input or additional income for the company of Rp. 1,632,000, - as for the details of the income obtained as in the table below. The above income is still gross because it has not been deducted by operational costs such as electricity, fish feed and wages for work. The size of the available and untapped land is $30 \times 1.5$ meters, so there is an expectation that ten times the income that will be obtained in the next process, which is around 16,320,000, - for one harvest.

Tabel 2. Aquaponic Profit Potency

\begin{tabular}{|c|l|c|c|c|}
\hline No & \multicolumn{1}{|c|}{ Product } & Result & Unit Price & \multicolumn{1}{c|}{ Total } \\
\hline 1 & $\begin{array}{l}\text { Kale } \\
(3 \text { months 3 times harvest x 72 } \\
\text { planting holes })\end{array}$ & 216 tie up & 2.000 & 432.000 \\
\hline 2 & $\begin{array}{l}\text { Parrot fish } \\
(200 \mathrm{head} / 5 \mathrm{head} / \mathrm{kg})\end{array}$ & $40 \mathrm{~kg}$ & 30.000 & 1.200 .000 \\
\hline
\end{tabular}

The next development will be carried out on a wider area to get bigger income, it is necessary to improve the electricity system by utilizing solar energy so that there will be savings in electricity costs in the long term.

\section{CONCLUSION}

As at the beginning, the purpose of this service was to help ease the burden on communities or companies affected by the impact of Covid-19 through applied aquaponic system technology, on this occasion the service was carried out at one of the companies engaged 
in tourism and sports that were affected by covid-19., as explained above, that the company gets the result in the form of additional income of Rp. 1,623,000, - / 3 months (one harvest) from the sale of vegetables and fish using the aquaponic system on idle land. Another advantage that you get from cultivating vegetables and fish is that the environment is beautiful, comfortable, has no smell, is beautiful and there are photo spots for those who visit this place. Some employees have been active again with this activity so that they get income even though they are not yet full as before. Companies will slowly rise from adversity due to covid-19.

\section{ACKNOWLEDGMENTS}

This service has been assisted by Unbaja students from several disciplines, also received material support and location support from the fostered partner company, namely $\mathrm{CV}$. Tirta Mas Raya both employees and management are very helpful in field implementation.

\section{REFFERENCY}

Alberto, A., Gennotte, V., Maiolo, S., Brigolin, D., Mélard, C., \&Pastres, R. (2018). Ecodesigning Aquaponics: a case study of an experimental production system in Belgium Procedia CIRP, 69(May), 546-550. https://doi.org/10.1016/j.procir.2017.11.064

Blidariu, F., \&Grozea, A. (2014).Increasing the Economical Efficiency and Sustainability of Indoor Fish Farming by Means of Aquaponics - Review. October 2011.

Budiman, M. W. (2018). Aquaponic Hand Book. DOC Player, Gersik-JawaTimur.

Company Profile of CV Tirta Mas Raya (2019), Sport Centre \& Entertainment Facility, West Serang- Banten.

Coordinating Ministry for Economic Affairs of the Republic of Indonesia. (2020). The Financial Services Authority issued a countercyclical policy as contained in a press release No. HM.4.6 / 32 / SET.M.EKON.2.3 / 03/2020.

Inmed. (2017). Jamaica Aquaponics Handbook. 128.

Saini, V. P. (2015). Aquaponics: Innovative farming Aquaponics: Innovative farming. November.

Timmons, M.B. and Ebeling, J.M. (2010). Recirculating Aquaculture. NRAC. 